\section{Characterization of the photosynthetic conditions and pigment profiles of the colour strains of Hypnea musciformis from field- collected and in vitro cultured samples}

\author{
Daniela R. P. Fernandes, ${ }^{1,2}$ Vanessa S. Caetano,,3 Márcio M. B. \\ Tenório, ${ }^{4}$ Fernanda Reinert, ${ }^{2,3}$ Yocie Yoneshigue-Valentin ${ }^{*, 1,2}$ \\ ${ }^{1}$ Laboratório de Botânica Marinha, Instituto de Biologia, Centro de Ciências \\ da Saúde, Universidade Federal do Rio de Janeiro, Brazil, \\ ${ }^{2}$ Programa de Pós-graduação em Biotecnologia Vegetal, Decania do Centro de \\ Ciências da Saúde, Universidade Federal do Rio de Janeiro, Brazil, \\ ${ }^{3}$ Laboratório de Fisiologia Vegetal, Instituto de Biologia, Centro de Ciências \\ da Saúde, Universidade Federal do Rio de Janeiro, Brazil, \\ ${ }^{4}$ Laboratório de Fitoplâncton, Instituto de Biologia, Universidade Federal do \\ Rio de Janeiro, Centro de Ciências da Saúde, Brazil.
}

\begin{abstract}
Hypnea musciformis (Wulfen) JV Lamour. is a species of great economic interest as it produces $\kappa$-carrageenan and has shown biological activities against HIV and HSV viruses. This species displays different colour strains in its natural habitat, which may have implications for the biotechnological potential of the species. The aim of this study was to characterize the photosynthetic apparatus and pigment profile of three colour strains of H. musciformis (green, brown and red) in their natural habitat and in culture. Chlorophyll $a$ fluorescence of photosystem II was measured with a pulse-amplitude modulated fluorometer and pigments were quantified by spectrofluorimetry (chlorophyll $a$ ) and spectrophotometry (phycobiliproteins). In the natural habitat, we detected significant differences between the colour strains for the following photochemical parameters: the green strain had a higher effective quantum yield (ФPSII) than the red strain and a higher maximum relative electron transport rate (rETRmax) than the brown and red strains. Saturation irradiances were $1000 \mu \mathrm{E} \cdot \mathrm{m}^{-2} \cdot \mathrm{s}^{-1}$ (green) and $500 \mu \mathrm{E} \cdot \mathrm{m}^{-2} \cdot \mathrm{s}^{-1}$ (brown and red). Concerning in vitro culture, the green strain presented the lowest ФPSII, rETRmax, and $\alpha \mathrm{rETR}$, while the brown strain presented the highest values for these same parameters. The chlorophyll a content of the cultured green strain was the lowest. The phycoerythrin contents of the three colour strains were unchanged by either natural of in vitro conditions: lower in green, intermediate in brown and higher in the red strain, ensuring the chromatic identity of the strains. Our results suggest that the green strain has a better performance when exposed to high irradiance, but a lower efficiency under low irradiance compared to the brown and red strains.
\end{abstract}

Revista Brasileira de Farmacognosia Brazilian Journal of Pharmacognosy 22(4): 753-759, Jul./Aug. 2012

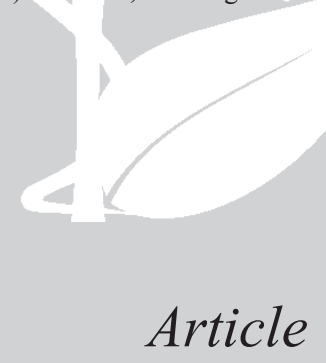

Received 1 Nov 2011 Accepted 8 Jan 2012 Available online 24 May 2012

Keywords: photosystem II chlorophyll $a$ phycobiliproteins colour strains Rhodophyta

ISSN 0102-695X http://dx.doi.org/10.1590/S0102$695 \times 2012005000064$

\section{Introduction}

The photosynthetic capacity of an organism can be characterized by chlorophyll $a$ fluorescence analysis (Bolhàr-Nordenkampf \& Öquist, 1993; Baker, 2008). This is a sensitive method, enabling instant and non-invasive measurements of living organisms in both the field and laboratory. It provides information about the ability of an organism to endure environmental stress by indicating, for example, damage to the photosynthetic apparatus. In photosynthesis, light energy is absorbed by a lightharvesting antenna complex and transferred to the reaction center of photosystem II (PSII) and then to photosystem
I (PSI), both located in the thylakoid membrane constituting the photochemical event. Excess energy not absorbed by the photochemical event is dissipated as heat and fluorescence, the non-photochemical events. Nonphotochemical quenching reduces the effective absorption of energy by the photosystem, thus avoiding damage to the photochemical apparatus (Bolhàr-Nordenkampf \& Öquist, 1993; Baker, 2008). Both photochemical and nonphotochemical events of light dissipation, determined by PSII fluorescence analysis in association with determination of the pigment profile, are valuable tools for the characterization of the photosynthetic apparatus of several organisms (Häder et al., 1997; Bautista \& Necchi 
2007; Yokoya et al., 2007).

PSII fluorescence, oxygen evolution and pigment profile analysis were used to characterize and evaluate the photosynthetic apparatus of two colour strains of cultured Hypnea musciformis (Wulfen) JV Lamour. (Yokoya et al., 2007). The strains were obtained from a single thallus with brown and green branches, the latter probably being a mutant (Yokoya et al., 2007). Both strains showed similar potential quantum yield of photosystem II (Fv/Fm) and effective quantum yield (F/Fm' = ФPSII) (Yokoya et al., 2007). However, the brown strain showed a higher maximumphotosyntheticrateand photosyntheticefficiency than the green strain. The pigment profile also differed between the colour strains; for instance, no phycoerythrin was detected in the green strain. Phycoerythrin gives a red colour to algae and can completely mask the green colour of chlorophyll $a$. Phycoerythrin plays an important role in the light-harvesting complexes (Neveux et al., 2006) and is one of the main nitrogen reserves in algae (Martínez \& Rico, 2002).

There are natural populations of $H$. musciformis in which the thalli have a single, apparently fixed colour at a given beach, such as the green epilitic colour strains and brown epiphytic colour strains in the State of Rio de Janeiro, Brazil (Reis \& Yoneshigue-Valentin, 1998). At another beach, only the red epilitic strain was found. The occurrence of such colour strains is a reflection of the relative concentration of chlorophyll $a$ and accessory pigments, sometimes of a deficiency of the latter (Yokoya et al., 2007). The occurrence of colour strains is common among Rhodophyta in genera such as Gracilaria Greville (Costa \& Plastino, 2011; Ursi \& Plastino, 2001); Eucheuma J. Agardh and Kappaphycus Doty (Gerung \& Ohno, 1997). Colour strains can be a result of either phenotypic acclimation to various light intensities (photoacclimation) or different genotypic adaptations (Kirk, 1994). Specimens with different pigment compositions may present different biochemical and physiological responses to abiotic factors (Kursar et al., 1983; Yokoya et al., 2007), different compositions of polysaccharides (Guimarães, 2000) and also different growth rates and pattern of photosynthesis (Guimarães, 2000; Ursi \& Plastino, 2001; Yokoya et al., 2007).

Photosynthetic characterization of the different naturally occurring colour strains of $H$. musciformis is of major importance for environmentally sustainable exploitation of such resources. H. musciformis has great economic value for the production of $\kappa$-carrageenan, an industrially important sulfated polysaccharide (Oliveira, 1998; Reis et al., 2006), and has shown antiviral activity against HSV (herpes simplex virus) and HIV (human immunodeficiency virus) (Neushul, 1990). H. musciformis also contains lectins, which have anti-inflammatory and hemagglutinating activity, besides being useful in cancer diagnosis (Nagano et al., 2002; Nagano et al.,
2005). Extracts of $H$. musciformis also proved to have anthelmintic, anti-inflammatory, myo-relaxing and antifungal action (Salimabi, 1980; Davies et al., 1984; Melo et al., 1997).

This study characterizes the photosynthetic apparatus and the pigment profiles of three colour strains of H. musciformis-green, brown, and red in both the field and in in vitro culture.

\section{Materials and Methods}

\section{Algal material}

Three colour strains of Hypnea musciformis (Wulfen) JV Lamour. were collected at the sublittoral fringe in Rio de Janeiro (RJ), Brazil. Green and brown strains were collected at Praia Rasa, Armação de Búzios (22 $\left.{ }^{\circ} 44^{\prime} 02^{\prime \prime S}-41^{\circ} 57^{\prime} 29^{\prime \prime} \mathrm{W}\right)$, and the red strain at Prainha, Arraial do Cabo (22 $\left.57^{\prime} 30^{\prime \prime S}-42^{\circ} 01^{\prime} 30^{\prime \prime} \mathrm{W}\right)$. Some samples were kept alive for fluorescence analysis in the field and in culture, while others samples were kept in a freezer for pigment analysis. To implement the culture, the apical segment of each colour strain was propagated by fragmentation of a single tetrasporophyte thallus, which yielded the clones. Three unialgal cultures were obtained from different colour strain clones using the protocol of Fernandes et al. (2011). The clones were maintained in controlled culture conditions with an irradiance of $35 \pm 5 \mu \mathrm{E} \cdot \mathrm{m}^{-2} \cdot \mathrm{s}^{-1}$ (measured with a LICOR LI-190 SA quantameter) at $22 \pm 1{ }^{\circ} \mathrm{C}$ in $12.5 \%$ Von Stosch stagnated culture medium (Edwards, 1970) with a salinity of 32 and a $12 \mathrm{~h}$ photoperiod. Ten apices of each colour strain (7 $\mathrm{mm}$ long) were placed in different flasks containing 500 $\mathrm{mL}$ of culture medium.

\section{Analysis of the photosynthetic apparatus}

The photosynthetic apparatus of the three colour strains of $H$. musciformis from the field and the in vitro culture was evaluated by measuring PSII fluorescence (FMS-2, Hansatech Instruments Ltd., KingsLynn, UK) with an amplified and modulated amber (540 nm) light pulse. Maximal quantum yield $(\mathrm{Fv} / \mathrm{Fm}=(\mathrm{Fm}-\mathrm{Fo}) / \mathrm{Fm})$ were obtained after $30 \mathrm{~min}$ of dark adaptation (Mouget \& Tremblim, 2002). Initial fluorescence was obtained using modulated light $<0.05 \mu \mathrm{E} \cdot \mathrm{m}^{-2} \cdot \mathrm{s}^{-1}$ (Mouget \& Tremblim, 2002), and maximum fluorescence by using a saturating light pulse $\left(0.7 \mathrm{~s} ; 15,300 \mu \mathrm{E} \cdot \mathrm{m}^{-2} \cdot \mathrm{s}^{-1}\right)$. Then, the same samples were measured in the light to evaluate the effective quantum yield $\left(\Phi P S I I=\left(F^{\prime}-F s\right) / F m^{\prime}\right)$ and non-photochemical quenching $\left(\mathrm{NPQ}=\left(\mathrm{Fm}-\mathrm{Fm} \mathrm{m}^{\prime}\right) / \mathrm{Fm}^{\prime}\right)$ (Mouget \& Tremblim, 2002). Rapid light curves (RLC) were obtained from the relative electron transport rate $($ rETR $=$ ФPSII.PAR.0.5) (Durako \& Kunzelman, 2002; Ralph \& Gademann, 2005). Light-adapted measurements 
were made on apical segments exposed to actinic light with a photosynthetically active radiation (PAR) range of $18-1033 \mu \mathrm{E} \cdot \mathrm{m}^{-2} \cdot \mathrm{s}^{-1}$.

All parameters reported were obtained approximately one hour after the thalli had been collected in the field, while measurements of in vitro cultured thalli were made $30 \mathrm{~min}$ after the lights were turned on. All measurements were made in a crystallizing dish with specimens immersed in $100 \mathrm{~mL}$ of the original medium: seawater for field specimens or Von Stosch culture medium for in vitro specimens. The light-emitting extremity of the fibre optic was immersed in the medium at a distance of 5 $\mathrm{mm}$ from the thallus apex. Four replicates were measured for each different strain/treatment.

\section{Pigment extraction and profile}

Chlorophyll $a(\mathrm{Chl} a)$ and phycobiliproteins (PHB) were analysed in the field samples and in vitro cultured samples. Wet frozen thalli were used $(n=4) ; 20$ $80 \mathrm{mg}$ of thalli were used for chlorophyll extraction and 150-270 mg for PHB extraction. Extraction procedures were performed in the dark. For chlorophyll extraction, thalli were macerated wrapped in a GF/F glass microfiber filter (Whatman) in a test tube with $6 \mathrm{~mL}$ of acetone $90 \%$ (Merck). The tubes was kept at $4{ }^{\circ} \mathrm{C}$ for $18 \mathrm{~h}$ for total extraction of $\mathrm{Chl} a$, centrifuged at $1800 \mathrm{rpm}$ for $5 \mathrm{~min}$ and the supernatant analysed by spectrofluorimetry (Varian Cary Eclipse spectrofluorimeter) according to Neveux \& Lantoine (1993), with the following modifications: 1) acquisition of a series of fifteen fluorescence emission spectra ranging in excitation wavelengths from 390$432 \mathrm{~nm}$ every $3 \mathrm{~nm}$. From each emission spectrum, we recovered a value every $2 \mathrm{~nm}$ between 659 to $715 \mathrm{~nm}$, thus totaling 435 measured fluorescence data points. The fluorescence excitation and emission slit widths were set at 5 and $10 \mathrm{~nm}$, respectively, and the photomultiplier voltage to $800 \mathrm{~V}$; 2) elimination of negative solutions was performed by using the least-squares approximation technique.

For PHB extraction, thalli were ground in a mortar with $6 \mathrm{~mL}$ of phosphate buffer $(0.1 \mathrm{M}, \mathrm{pH} 6.5)$ and poured into a test tube. The PHBs extracted were phycoerythrin $(\mathrm{PE})$, phycocyanin $(\mathrm{PC})$, and alophycocyanin (APC). Prior to analysis, the extracts were maintained at $4{ }^{\circ} \mathrm{C}$ for $16 \mathrm{~h}$ and centrifuged at $1800 \times g$ for $5 \mathrm{~min}$. The concentrations of PE, PC and APC were obtained by measuring the absorbance of the supernatants with a spectrophotometer (80 Cirrus ST, Femto) and using the equations of Kursar et al. (1983).

\section{Data analysis}

Following normality (Kolmogorov-Smirnov's) and homoscedasticity (Levene's) tests, data were analysed using factorial analysis of variance (one-way and two-way ANOVA) and, if necessary, Tukey`s test $(p<0.05 \%)$ using Statistica software v.7 (StatSoft, Inc., 2004).

\section{Results and Discussion}

\section{Photosynthetic parameters}

The potential quantum yield $(\mathrm{Fv} / \mathrm{Fm})$ of the three colour strains did not differ between field samples $(\mathrm{F}=0.45$, $p=0.645)$ or in vitro cultured specimens ( $\mathrm{F}=0.57, p=0.577)$ (Table 1). Previous studies reported similar Fv/Fm values under natural conditions (around 0.6 r.u.) for Rhodophyta species (Mouget \& Tremblim, 2002; Figueroa et al., 2009; Chaloub et al., 2010). Higher Fv/Fm values were repoted for in vitro cultured Hypnea musciformis (Wulfen) JV Lamour. strains (Yokoya et al., 2007) than those reported here. In the natural habitat, the green colour strain had the highest effective quantum yield (ФPSII), while the red strain had the lowest $(\mathrm{F}=79.12, p<0.010)$. Under the low light conditions of the in vitro culture, the green colour strain had the lowest $\Phi$ PSII among the colour strains $(\mathrm{F}=68.02, p<0.010)$ (Figure 1). The rapid light curves are shown in Figure 1. In the natural habitat, the green strain showed the highest rETRmax $(\mathrm{F}=10.95, p=0.002)$ (Figure 2 ) and the highest light saturation point (around 1,000 $\left.\mu \mathrm{E} \cdot \mathrm{m}^{-2} \cdot \mathrm{s}^{-1}\right)$. However, the photosynthetic efficiencies $(\alpha$ rETR) were similar among the three strains (Table 1). The brown and red strains showed similar light saturation points, approximately $50 \%$ lower than that of the green strain (around $500 \mu \mathrm{E} \cdot \mathrm{m}^{-2} \cdot \mathrm{s}^{-1}$ ). In culture, the brown strain had the highest rETRmax and the green strain the lowest $(\mathrm{F}=18.40, p<0.001)$. The same pattern was observed for $\alpha$ rETR. All colour strains saturated at around $56 \mu \mathrm{E} . \mathrm{m}^{-}$ ${ }^{2} \cdot \mathrm{s}^{-1}$. The green strain was the most efficient under natural high light conditions among the three colour strains and showed the lowest photosynthetic yield under low light culture condition. Non-photochemical quenching (NPQ) drains excitation energy and prevents damage to the photochemical apparatus (Mouget \& Tremblim, 2002; Baker, 2008). The NPQ was equivalent for all colour strains under both growth conditions, although, as expected, considerably lower in culture (Figure 3). Under low light, only a small portion of the energy entering the photosynthetic process $(3 \%)$ is dissipated through heat emission and fluorescence (Bolhár-Nordenkampf \& Oquist, 1993). Large amounts of light energy cannot be fully utilized by the photochemical process and the excess energy therefore has to be dissipated (Falkowski $\&$ Raven, 2007). The photosynthetic characterization of the three strains suggests that the green strain copes more efficiently under high light conditions but less efficiently under low light conditions than the brown and red strains. Additionally, the $\Phi$ PSII and rETRmax parameters appear to be more sensitive than $\mathrm{Fv} / \mathrm{Fm}$ for the evaluation of the 
photochemical performance of the colour strains because it was able to differentiate between them both in situ and in vitro.

\section{Pigment profiles}

The content of Chl $a$ did not differ significantly between the three colour strains in the natural habitat $(\mathrm{F}=0.67, p=0.545)$. Under in vitro culture conditions, the concentration of $\mathrm{Chl} a$ differed significantly only between the green strain and the others two colour strains $(\mathrm{F}=112.89, p<0.001)$, with a reduction of $32.6 \%$ in the content (Figure 4). The photochemical process is influenced primarily by irradiance and the Chl $a$ concentration (Dring, 1982). The observed decrease in the $\mathrm{Chl} a$ concentration in the green strain in culture may be related to the lower $\Phi$ PSII shown by this strain in vitro. Regarding the phycobiliproteins, $\mathrm{PE}$ was the major pigment in the three colour strains and, being the dominant pigment in Rhodophyta, (Kirk, 1994; Van den Hoek et al., 1995). The colour of each strain is directly related to the observed PE concentration gradient (Figure 4). However, only the green strain differed from the other two strains (Field: $\mathrm{F}=28.55, p<0.001$; In vitro $\mathrm{F}=16.31, p=0.004$ ). The phycoerythrin content was lower in the in vitro cultured strains compared to the natural habitat: a $13.81 \%$ decrease for the green, $53.53 \%$ for the brown and $61.15 \%$ for the red strain (Figure 4). Importantly, the green colour strain of $H$. musciformis, unlike other green strains found in Rhodophyta (Yokoya et al., 2007; Costa \& Plastino,

Table 1. Maximal quantum yield (Fv/Fm-r.u), relative electron transport rate (rETRmax- $\left.\mu \mathrm{E} \mathrm{m}^{-2} \mathrm{~s}^{-1}\right)$, photosynthetic efficiency ( $\alpha$ rETR) of green (Grn), brown (Bro) and red (Red) colour strains of Hypnea musciformis in the field (F) and under culture (C) conditions. Values shown are the means and $( \pm)$ standard deviations. The letters indicate significant differences according to twoway ANOVA $(p<0.05)$.

\begin{tabular}{lcccccc}
\hline & \multicolumn{3}{c}{ Field } & \multicolumn{2}{c}{ Culture } \\
\hline Parameters & Grn & Bro & Red & Grn & Bro & Red \\
Fv/Fm & $0.62 \pm 0.03$ & $0.61 \pm 0.03$ & $0.60 \pm 0.04$ & $0.44 \pm 0.08$ & $0.49 \pm 0.06$ & $0.46 \pm 0.06$ \\
rETR $_{\max }$ & $39.78 \pm 1.03$ & $27.05 \pm 4.44$ & $23.57 \pm 7.64$ & $4.53 \pm 0.43 \mathrm{a}$ & $10.37 \pm 2.43 \mathrm{~b}$ & $6.80 \pm 0.99 \mathrm{ab}$ \\
$(\alpha$ rETR $)$ & $0.27 \pm 0.2$ & $0.23 \pm 0.02$ & $0.21 \pm 0.05$ & $0.05 \pm 0.02 \mathrm{a}$ & $0.19 \pm 0.02 \mathrm{~b}$ & $0.14 \pm 0.02 \mathrm{c}$ \\
\hline
\end{tabular}
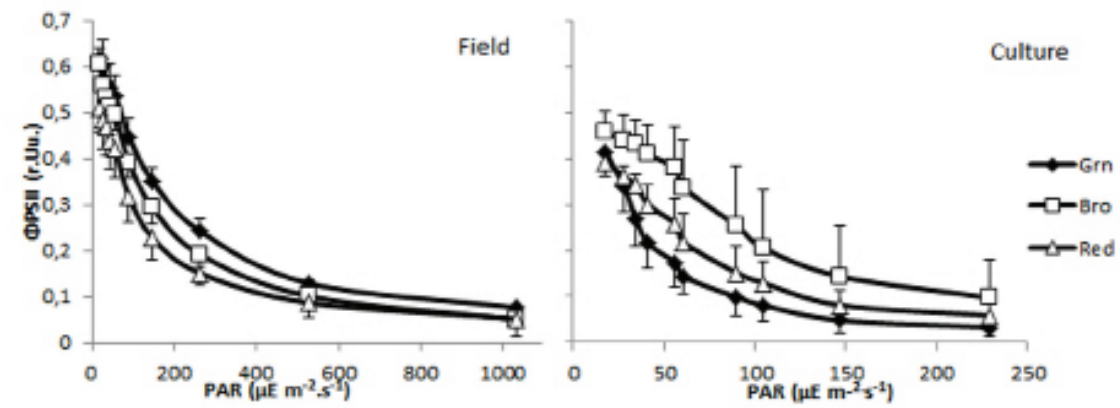

Figure 1. Effective quantum yield ( $\Phi$ PSII) as a function of the irradiance for green (Grn), brown (Bro) and red (Red) colour strains of Hypnea musciformis in the field and under culture conditions. The symbols are the means and the bars indicate the standard deviations.

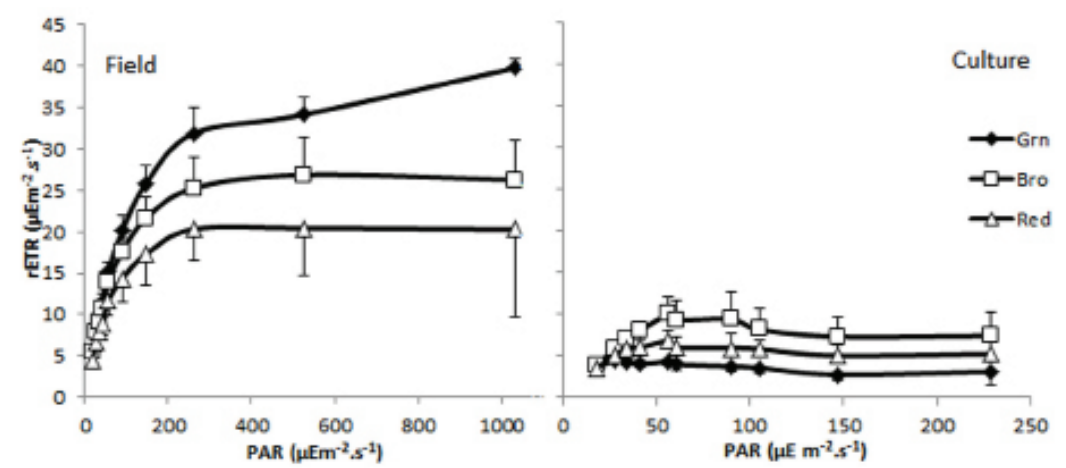

Figure 2. Rapid light curves of the relative electron transport rate (rETR) as a function of the irradiance for green (Grn), brown (Bro) and red (Red) colour strains of Hypnea musciformis in the field and under culture conditions. The symbols are the means and the bars indicate the standard deviations. 


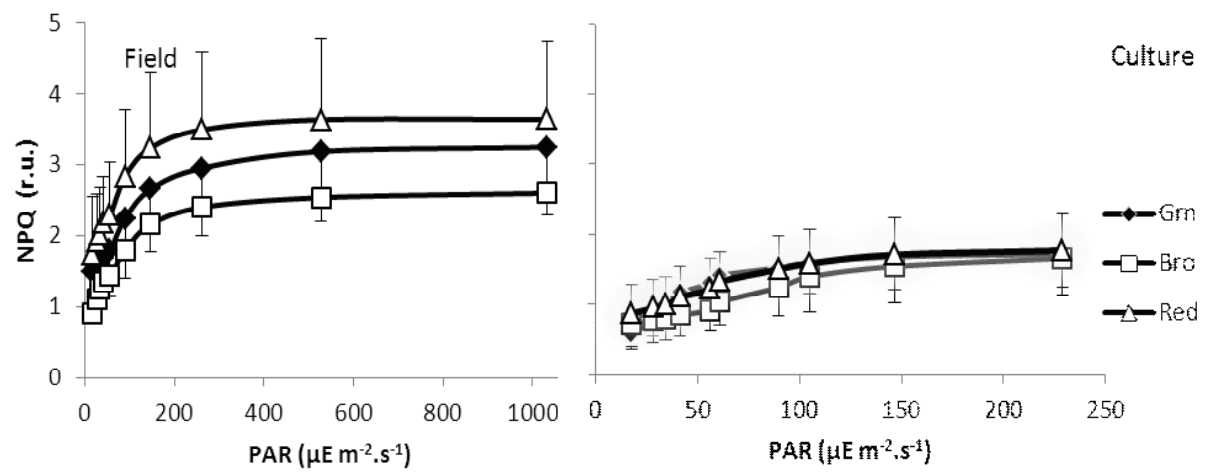

Figure 3. Non-photochemical quenching (NPQ) as a function of the irradiance for green (Grn), brown (Bro) and red (Red) colour strains of Hypnea musciformis in the field and under culture conditions. The symbols are the means and the bars indicate the standard deviations.

2011) showed the presence of PE. Regarding the content of PC, there was no evidence of significant differences between the strains for field samples $(\mathrm{F}=5.07, \mathrm{p}=0.051)$ or in the in vitro culture $(\mathrm{F}=2.08, \mathrm{p}=0.206)$. There was a reduction of $76.66 \%$ in the concentration of $\mathrm{PC}$ for the in vitro cultured strains in relation to the field ones (Figure 4). Alophycocyanin concentrations in the green strain differed from that of the red strain in the natural habitat $(F=6.91, p=0.278)$. Under culture conditions, the green strain had a concentration of APC significantly different from that of the other two strains $(F=112.89, p<0.001)$. Compared to the natural habitat, the concentration of APC was reduced $48.39 \%$ in the three colour strains in culture. The relative contributions of each pigment for the three strains are shown in Figure 5.

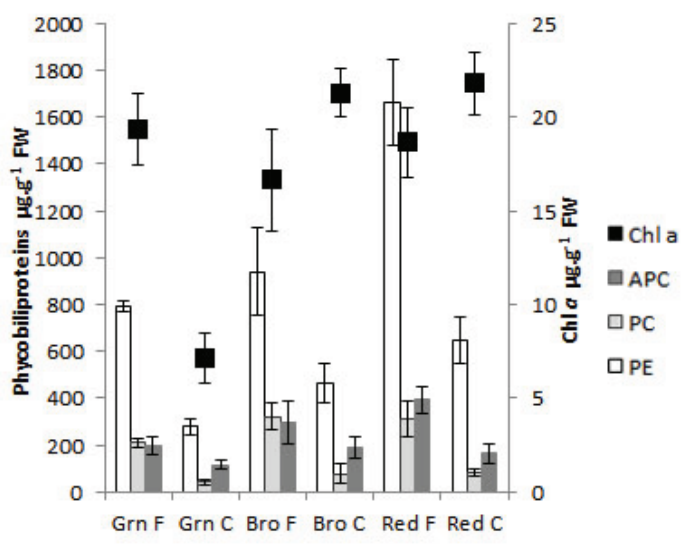

Figure 4. Concentrations ( $\mu \mathrm{g} \cdot \mathrm{g}^{-1}$ fresh weight) of chlorophyll $\mathrm{a}$ and the phycobilliproteins (phycoerythrin (PE), phycocyanin (PC) and alophycocyanin (APC) for green (Grn), brown (Bro) and red (Red) colour strains of Hypnea musciformis in the field (F) and under culture (C) conditions.

During approximately one year of in vitro culture, the colour of the three strains was maintained, although less intense in the brown and the red strains compared to the natural habitat. The maintenance of the proportionality of phycobiliproteins, especially phycoerythrin, ensures the chromatic identity of the colour strains. This was found previously in other Rhodophyta colour strains (Costa \& Plastino, 2001, 2011; Yokoya et al., 2007). This suggests that different colours are not the result of chromatic adaptation to naturally occurring environmental variations. To better characterize these strains, morphological and molecular analysis, as well as the photosynthetic responses to variations in the quality and/or quantity of light are needed.

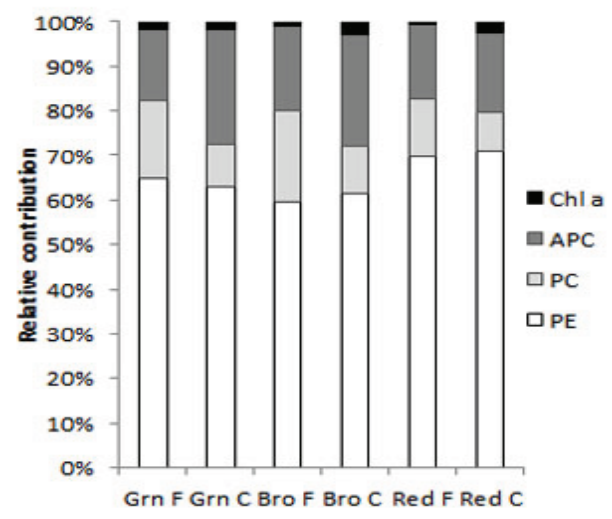

Figure 5. Relative contributions of chlorophyll a and the phycobilliproteins-phycoerythrin (PE), phycocyanin (PC) and alophycocyanin (APC) for green (Grn), brown (Bro) and red (Red) colour strains of Hypnea musciformis in the field (F) and under culture $(\mathrm{C})$ conditions.

\section{Acknowledgments}

The authors are grateful to the Coordination of Superior Level Staff Improvement (CAPES) and the Brazilian National Council for Scientific and Technological Development (CNPq) for $\mathrm{PhD}$ grants to the first and second authors [Post-Graduate Programme in Plant Biotechnology, Federal University of Rio de Janeiro 
(UFRJ)] and for financial support of the fifth author (CNPq-Process number 309929/2009-1).

\section{References}

Baker N 2008. Chlorophyll Fluorescence: A probe of photosynthesis in vivo. Annu Rev Plant Biol 59: 89-113.

Bautista AIN, Necchi O 2007. Photoacclimation in three species of freshwater red algae. Braz J Plant Physiol 19: 23-34.

Bolhàr-Nordenkampf HR, Öquist G 1993. Chlorophyll fluorescence as a tool in photosynthesis research. In: Hall DO, Scurlock JMO, Bolhàr-Nordenkampf HR, Leegood $\mathrm{RC}$, Long SP (org.). Photosynthesis and production in a changing environment: a field and laboratory manual. London: Chapman \& Hall, p. 193-206.

Chaloub RM, Reinert F, Nassar CAG, Fleury BG, Mantuano DG, Larkum AWD 2010. Photosynthetic properties of three Brazilian seaweeds. Rev Bras Bot 33: 371-374.

Costa VL, Plastino EM 2001. Histórico de vida de espécimens selvagens e variantes cromáticas de Gracilaria birdiae (Gracilariales, Rhodophyta). Rev Bras Bot 24: 491-500.

Costa VL, Plastino EM 2011. Color inheritance and pigment characterization of red (wild- type), greenish-brown, and green strains of Gracilaria birdiae (Gracilariales, Rhodophyta). J Appl Phycol 23: 599-605.

Davies LP, Jamieson DD, Baird-Lambert JA, Kazlauskas R 1984. Halogenated pyrrolopyrimidine analogs of adenosine from marine organisms, pharmacological activities and potent inhibition of adenosine kinase. Biochem Pharmacol 33: 347-356.

Dring MJ 1982. Photosynthesis in the sea. In: Dring MJ. The Biology of Marine Plants. Great Britain: Edward Arnold, p. 44-64.

Durako MJ, Kunzelman JI 2002. Photosynthetic characteristics of Thalassia testudinum measured in situ by pulse-amplitude modulated (PAM) fluorometry: methodological and scale-based considerations. Aquat Bot 73: 173-185.

Edwards P 1970. Illustrated guide to the seaweeds and sea grasses in the vicinity of Porto Aransas, Texas. Contrib Mar Sci 15: 1-228.

Falkowski PG, Raven JA 2007. Aquatic photosynthesis. Princeton: Princeton University Press.

Fernandes DRP, Yokoya NS, Yoneshigue-Valentin Y 2011. Protocol for seaweed decontamination to isolate unialgal cultures. Rev Bras Farmacogn 21: 313-316.

Figueroa FL, Martínez B, Israel A, Neori A, Malta EJ, Ang Jr P, Inken S, Marquardt R, Rachamim T, Arazi U, Frenk S, Korbee N 2009. Acclimation of red sea macroalgae to solar radiation: photosynthesis and thallus absorbance. Aquat Biol 7: 159-172.

Gerung GS, Ohno M 1997. Growth rates of Eucheuma denticulatum (Burman) Collins et Harvey and Kappaphycus striatum (Schmitz) Doty under different conditions in warm waters of Southern Japan. J Appl
Phycol 9: 413-415.

Guimarães M 2000. Aspectos fisiológicos de Gracilaria domingensis (Gracilariales, Rhodophyta): subsidios para a compreensão da manutenção do polimorfismo pigmentar. São Paulo, 89 p. Tese de Doutorado, Universidade de São Paulo.

Häder DP, Lebert M, Flores-Moya A, Jiménez Z, Mercado J, Salles S, Aguilera J, Figueroa FL 1977. Effects of solar radiation on the photosynthetic activity of the red alga Corallina elongate Ellis et Soland. $J$ photoch photobio B 37: 196-202.

Kirk JTO 1994. Light \& photosynthesis in aquatic ecosystems. Cambridge: Cambridge University Press.

Kursar TA, Van Der Meer J, Alberte RS 1983. Light-harvesting system of the red alga Gracilaria tikvahiae. I. Biochemical analyses of pigment mutations. Plant Physiol 73: 353-360.

Martínez B, Rico JM 2002. Seasonal variation of P content and major $\mathrm{N}$ pools in Palmaria palmata (Rhodophyta). $J$ Phycol 38: 1082-1089.

Melo VMM, Medeiros DA, Rios FJB, Castelar LIM, Carvalho AD 1997. Antifungal properties of proteins (agglutinins) from the red alga Hypnea musciformis (Wulfen) Lamouroux. Bot Mar 40: 281-284.

Mouget J, Tremblim G 2002. Suitability of the fluorescence monitoring system (FMS, Hansatech) for meansurement of photosynthetic characteristics in algae. Aquat Bot 74: 219-231.

Nagano CS, Moreno FBMB, Bloch C, Prates MV, Calvete JJ, Saker-Sampaio S, Farias WRL, Tavares TD, Nascimento KS, Grangeiro TB, Cavada BS, Sampaio AH 2002. Purification and characterization of lectins from the red marine alga Hypnea musciformis. Prot Pept Letters 9: 159-165.

Nagano CS, Debray H, Nascimento KS, Pinto VPT, Cavada BS, Saker-Sampaio S, Farias WRL, Sampaio AH, Calvete JJ 2005. HCA and HML isolated from the red marine algae Hypnea cervicornis and Hypnea musciformis define a novel lectin family. Prot Sci 14: 2167-2176.

Neushul M 1990. Antiviral carbohydrates from marine red algae. Hydrobiologia 204/205: 99-104.

Neveux J, Lantoine F 1993. Spectrofluorometric assay of chlorophylls and phaeopigments using the least squares approximation technique. Deep-Sea Res Oceanogr Res Pap 40: 1747-1765.

Neveux J, Tenório, MMB, Dupouy C, Villareal TA 2006. Spectral diversity of phycoerythrins and diazotroph abundance in tropical waters. Limnol Oceanogr 51: 1689-1698.

Oliveira EC 1998. The seaweed resources of Brazil. In: Crithcley AT, Ohno M (org.). Seaweeds resources of the world. Yokosuka: Japan International Cooperation Agency, p. 366-371.

Ralph P, Gandemann R 2005. Rapid light curves: A powerful tool to asses photosynthetic activity. Aquat Bot 82: 222237. 
Characterization of the photosynthetic conditions and pigment profiles of the colour strains of Hypnea musciformis from field-collected and in vitro

Reis RP, Caldeira AQ, Miranda APS, Barros-Barreto MB 2006. Potencial para maricultura da carragenófita Hypnea musciformis (Wulfen) J.V. Lamour. (Gigartinales Rhodophyta) na Ilha da Marambaia, Baía de Sepetiba, RJ, Brasil. Acta Bot Bras 20: 763-769.

Reis RP, Yoneshigue-Valentin Y 1998. Variação espaço-temporal de populações de Hypnea musciformis (Rhodophyta, Gigartinales) na Baía de Sepetiba e Armação dos Búzios, Rio de Janeiro, Brasil. Acta Bot Bras 12: 465-483.

Salimabi BD 1980. Antispasmodic and anti-inflammatory activity of carrageenan from Hypnea musciformis Wulfen. Indian J Pharmacol 1: 259-261.

Ursi S, Plastino EM 2001. Crescimento in vitro de linhagens de coloração vermelha e verde clara de Gracilaria birdiae (Gracilariales, Rhodophyta) em dois meios de cultura: análise de diferentes estádios reprodutivos. Rev Bras Bot 24: 587-594.
Van den Hoek C, Mann DG, Jahns HM 1995. Algae: An introduction to phycology. Cambridge: University Press.

Yokoya YS, Necchi Jr O, Martins AP, Gonzalez SF, Plastino EM 2007. Growth responses and photosynthetic characteristics of wild and phycoerythrin-deficient strains of Hypnea musciformis (Rhodophyta). J Appl Phycol 19: 197-205.

\section{*Correspondence}

Yocie Yoneshigue-Valentin

Laboratório de Botânica Marinha, Instituto de Biologia, Universidade Federal do Rio de Janeiro, CCS, sl A1-094, Av. Carlos Chagas Filho, 373. 21941-902 Rio de Janeiro-RJ, Brasil yocie@biologia.ufrj.br 